\title{
Ascensão de uma norma endógena do português em Moçambique: desafios e perspectivas
}

Gregório Domingos Firmino ${ }^{a}$

\begin{abstract}
RESUMO
O artigo apresenta a situação da língua portuguesa em Moçambique, mostrando aspectos relacionados com o percurso da sua implantação no país, desde o período colonial até ao momento actual. Depois de evidenciar aspectos históricos desta implantação, o artigo aponta que a língua portuguesa está num processo de nativização simbólica e estrutural, de que emergem formas peculiares do seu uso. Por fim, o artigo discute os desafios e perspectivas que a nativização impõe, face a necessidade do reconhecimento de uma norma endógena.
\end{abstract}

Palavras-chave: Moçambique. português. nativização. norma. padronização.

\section{a Universidade Eduardo Mondlane, Faculdade de Letras e Ciências Sociais, Maputo, Moçambique.}

E-mail: gregoriofirmino@gmail.com

\section{Como citar:}

Firmino, G. D. Ascensão de uma norma endógena do português em Moçambique: desafios e perspectivas. Gragoatá, Niterói, v.26, n.54, p. 163-192, 2021. <https://doi.org/10.22409/gragoata.v26i54.46324> 


\section{Introdução}

A partir do século XV assiste-se ao surgimento da influência europeia em vários cantos do globo, na sequência da expansão marítima europeia, de que resultou o contacto e/ou conquista de territórios e povos na América, África e Ásia. Em África, o apogeu desta influência ocorre a partir de finais do século XIX quando as potências europeias, perseguindo o seu objectivo imperialista de exploração dos recursos disponíveis em África, repartem os territórios africanos entre si. Assim, para a materialização da sua ocupação efectiva, as potências coloniais estabeleceram um mecanismo de gestão que garantisse o seu controle político-administrativo, económico, social e cultural e, neste âmbito, para além de outras medidas, foi imposta a língua da potência colonial, que se tornou num instrumento essencial do exercício do poder colonial. Progressivamente, acaba sendo adoptada por segmentos da população autóctone e, inclusivamente, é através da língua colonial que posteriormente se articula o discurso nacionalista anticolonial que, eventualmente, conduziu à revolta contra o colonialismo e à criação de estados independentes, tal como, na peça de Shakesapeare, The tempest, vista como um "um libelo anticolonial contestando o direito do domínio europeu sobre o Novo Mundo" (SHAKESPEARE, 2014, p. 9), a personagem Caliban indicara: "You taught me language; and my profit on't/ Is, I know how to curse./The red plague rid you/For learning me your language"1 (ASHCROFT, 2001, p. 96; ASHCROFT, 2009, p. 17; SHAKESPEARE, 2014, p. 62). Tendo sido um veículo para imaginação destas novas nações independentes e sendo património das elites que promoveram as lutas anticoloniais, as línguas de origem europeia são adoptadas como línguas oficiais e/ou nacionais nos novos estados-nação (MAKONI; MAKONI; ABDELHAY; MASHIRI, 2012, p. 523-543)

A implantação das línguas europeias na América, África e Ásia implicou a sua adaptação aos novos ambientes em que eram usadas, ocasionando a sua progressiva transformação, de que resultaram as chamadas "variedades não-nativas". (KACHRU, 1981, p. 15), ou seja, formas linguísticas presentes fora do território europeu original, que sofrem um processo de nativização, tal como tem sido descrito para o inglês, com os chamados "new-englishes" (BOKAMBA, 1982; KACHRU, 
1982; LOWENBERG, 1986; SCHNEIDER, 2007; TUNDE-AWE, 2014 e outros), para o francês (BOURHIS, 1982; FÉRAL, 2010-1; MANNESSY, 1989), para o espanhol (LISPKI, 1985, 2004), e para o português (FERREIRA, 1988; FIRMINO, 2005; GONÇALVES, 2010, 2013; INVERNO, 2009; MATEUS, 2005). Ao passar pela nativização, a língua de origem europeia integra-se numa nova ecologia adquirindo novas funções, novos usos e novas características estruturais decorrentes do novo contexto em que está inserida. Assim, a emergência de uma variedade nativizada implica uma mudança sócio-simbólica bem como a incorporação de novos traços estruturais que as diferenciam das variedades europeias, cuja génese está na influência das línguas de substracto. De facto, o modelo europeu é subvertido, com a ocorrência de desvios, que não são vistos como erros linguísticos, ou seja, são formas produtivas socialmente aceites relacionadas com o novo ambiente linguístico-cultural, com um carácter mais sistémico que idiossincrático.

O modelo dinâmico proposto por Schneider (2007) para explicar a emergência de variedades nativizadas póscoloniais do inglês (PCEs, para post-colonial english) argumenta que nativização é seguida pela estabilidade endonormativa, que ocorre depois da independência ou outro grande evento transformador ("event X", como designa Schneider (2007, p. 49), em que uma norma linguística local é aceite e carrega consigo a simbolização de uma identidade nacional pan-étnica. Esta norma local cria também a ideia de uma homogeneidade linguística, marcada por um trabalho de codificação, preparação de dicionários e descrição gramatical, para além do seu uso na criatividade literária. Num outro modelo, proposto por Moag (1982, p. 271) a estabilidade endonormativa ocorre com a institucionalização da variedade nativizada, que se torna numa língua legitimada pela intelligentsia local, como escritores e professores, bem como pelos media e materiais escolares. É através da legitimação de uma nova norma que se consuma a diferenciação em relação ao modelo europeu.

A presente comunicação debruça-se sobre a implantação da língua portuguesa em Moçambique, descrevendo a sua transformação simbólica e estrutural, que ocorre acentuadamente na sequência da sua adopção como língua oficial e símbolo de unidade nacional, depois da independência em 1975. Começará por fazer referência ao processo da sua 
disseminação, mostrando, sumariamente, os seus antecedentes históricos. Seguidamente, apontará que a língua portuguesa em Moçambique está num processo de nativização, de que emerge uma variedade heterogénea com traços endógenos, num ambiente em que a norma europeia da língua portuguesa ainda é formalmente influente. Há uma heterogeneidade linguística nos variados usos da língua portuguesa num ambiente em que exonormatividade é formalmente imposta, por exemplo, no contexto escolar, enquanto que a endonormatividade é socialmente dominante na vida quotidiana.

\section{Implantação do português em Moçambique: factos históricos}

O processo de implantação da língua portuguesa em Moçambique associa-se ao próprio processo de colonização portuguesa. Embora a presença portuguesa remonte a 1498, aquando da famosa viagem marítima à Índia de Vasco da Gama, somente no século XX se inicia a posse efectiva de Moçambique, depois das campanhas de ocupação empreendidas para dar seguimento às deliberações da Conferência de Berlim. Os entendimentos de Berlim, que tinham o objectivo de gerir conflitos territoriais que opunham as potências coloniais entre si, impunham que cada potência colonial provasse a ocupação efectiva dos seus territórios, através de acordos com líderes locais, gestão administrativa, flutuação da bandeira e manutenção da ordem por meio de uma força policial (CRAVEN, 2015, p. 43). Reconhecido o poder de ocupação, a potência colonial podia explorar economicamente o território. Deste modo, as autoridades portuguesas conduziram campanhas de ocupação militar, nas últimas décadas do século XIX e nas primeiras duas décadas do $X X$, que permitiram o controlo do território e a imposição da sua autoridade, ao que se seguiu a concepção e implementação de políticas socioeconómicas para a exploração da colónia, principalmente depois da implantação da república, em 1910, e estabelecimento do Estado Novo, em 1933. Para o efeito, há um novo enquadramento jurídico que explicita a nova política colonial republicana, sendo o Acto Colonial de 1930, cuja versão final foi aprovada em 1935, com a Lei $\mathrm{n}^{\circ} 1900$ de 21 de Maio de 1935, um dos aspectos mais significativos. 
Inicialmente, o território foi dividido em duas partes, sendo que o norte ficou sob o controlo de empresas concessionárias, ficando a administração portuguesa concentrada na zona sul, que passa a ser considerada como reservatório de mão de obra para as minas da África do Sul, dada a sua proximidade com a África do Sul, onde se operava um boom na indústria mineira. Numa fase posterior, o estado colonial tomou o controlo administrativo de todo o território e as empresas concessionárias perdem algumas prerrogativas (NEWITT, 2018, p. 122). A proximidade com a África do Sul, onde se operava um crescimento na indústria mineira, promoveu o desenvolvimento da cidade de Lourenço Marques (actual cidade de Maputo, capital da República de Moçambique), já capital da colónia desde 1898 (MELO, 2013, p. 74), que passa a servir a África do Sul, através do seu porto e da linha férrea que a ligava a Transvaal. Deste modo, a cidade de Lourenço Marques transformou-se no principal centro político-administrativo, económico e cultural da colónia. Este desenvolvimento da cidade de Lourenço Marques ditou necessidades crescentes de mão de obra, que não podiam ser suficientemente suprimidas com a imigração de colonos. Daí a incorporação da população local, o que viria a ser o primeiro grupo de africanos com habilidades para se integrar no sistema socioeconómico colonial vigente na cidade de Lourenço Marques. Uma vez que estas habilidades incluíam o domínio da língua portuguesa, este grupo de africanos terá sido o primeiro núcleo de falantes desta língua no seio da população autóctone, que interagia com os colonos dentro das instituições coloniais e empresariais que operavam na urbe. Porém, na cidade, outras línguas, para além do português, eram também faladas, como o caso, obviamente, das línguas autóctones, principalmente o xironga, ou do inglês, que era muito importante nos contactos e negócios com a África do Sul, e nas igrejas protestantes, onde muitos africanos estavam afiliados. Contudo, o português distinguia-se, em certo grau, também o inglês, por garantir mobilidade social, assegurando melhores empregos e consequente prestígio social. O português garantia igualmente a cidadania a africanos (negros), afroeuropeus (mestiços) e afro-asiáticos (indianos) considerados assimilados/civilizados, em oposição aos considerados indígenas não-civilizados (NEWITT, 2018, p. 114), conforme 
estipulado em vários documentos legais coloniais, como o Regulamento do Trabalho Indígena, de 1899, o Regulamento do Trabalho dos Indígenas na Colónia de Moçambique, de 1930, a Carta Orgânica do Império Colonial Português e Reforma Administrativa Ultramarina, de 1933, ou o Estatuto dos Indígenas Portugueses das Províncias da Guiné, Angola e Moçambique, de 1954 (MARTINEZ, 2008, p. 196; NEWITT 1995, p. 383, p. 441-442). O assimilado era considerado cidadão português, devendo apresentar um conjunto de características, de entre elas, falar correctamente a língua portuguesa, conforme indica conforme indica Escola Superior Colonial (1954, p. 112 apud MINDOSO, 2017, p. 76).

Embora a condição de assimilado implicasse um “aportuguesamento", oscidadãos não perdiama sua africanidade, sendo, muitas vezes, um fingimento para se beneficiar de uma vida melhorada. Os assimilados, que constituíam uma classe média africana, eram sociolinguisticamente "diglóssicos" em alguns casos, "triglóssicos". Dominavam as línguas locais, que usavam em domínios baixos, e o português e/ou inglês, nos domínios altos, em consonância com o facto de flutuarem em dois mundos distintos.

A ausência de uma rede escolar adequada impedia a massificação da assimilação, pelo que o número de africanos que ascenderam à condição de assimilados foi muita reduzida (NEWITT, 1995, p. 400, p. 442-443). De facto, muito mais do que a reduzida rede escolar, a própria lógica da colonização portuguesa encerrava paradoxos que tornavam impossível o projecto de assimilação (MACAGNO, 2020). Apesar disso, o grupo de assimilados acabou tendo uma influência social significativa, porque representava o modelo de ascensão social dentro dos limites impostos pela sociedade colonial. A consequência linguística é que o português se torna num capital social fundamental no investimento pela mobilidade social, criando-se, assim, um precedente que tem perdurado na sociedade moçambicana até aos tempos actuais.

Quando Moçambique obtém a sua independência em 1975, herda-se um cenário linguístico em que a maioria da população é falante materna de uma das várias línguas autóctones africanas. Mesmo os poucos falantes da língua portuguesa, que resultaram do sistema assimilacionista, estão concentrados nos meios urbanos e têm, na sua maioria, uma 
língua africana como língua materna. Outras línguas eram faladas como língua materna, nomeadamente línguas de origem asiática, dada a existência de emigrantes oriundos da Índia e suas proximidades.

Apesar de a língua portuguesa ser minoritária, conhecida como uma língua segunda pela maioria dos seus falantes, é adoptada como língua oficial, conforme veio a ser confirmado na segunda e terceira constituição de Moçambique, de 1990 e 2004, cujos Artigos 5 e 10, respectivamente, explicitamente indicam que "Na República de Moçambique a língua portuguesa é a língua oficial". A primeira constituição que vigorou desde 1975, tirando o sintomático facto de estar escrita em português, não fez nenhuma menção a línguas, talvez porque parecesse óbvio que a língua portuguesa tivesse que ser a língua oficial. Vários factores apontam nesse sentido. A Frente de Libertação de Moçambique (FRELIMO), que assume o poder num regime unipartidário, já usara a língua portuguesa durante a fase da luta armada contra o colonialismo português, como forma de garantir a unidade no seio do movimento nacionalista. Dada a diversidade linguístico-cultural do país, não havia uma língua autóctone que pudesse servir como língua franca por todo o território moçambicano. As várias línguas africanas estavam circunscritas a espaços regionais e étnicos específicos e não tinham uma história de uso em contextos oficiais e formais. Pelo contrário, o português, embora não fosse conhecido pela maioria da população, tinha falantes espalhados por todo o país e o seu uso em funções oficiais estava já enraizado na sociedade. Com efeito, o exercício de poder associava-se ao uso de português, dada a história colonial ou o próprio funcionamento da FRELIMO. De facto, os que deveriam ser cooptados para o exercício de poder, isto é, as elites sociais, afirmavam-se pelo carácter distintivo que o domínio da língua portuguesa lhes concedia. Este domínio da língua portuguesa, e não das outras línguas africanas, acabava por ser a habilidade imprescindível para operar nas instituições de gestão do estado. Contudo, há razões para se concluir que a principal motivação para uso oficial da língua portuguesa deriva do projecto de edificação de um estado-nação em que o princípio da unidade nacional, acima das segmentações étnicas, regionais ou raciais, era um objectivo primordial. O pilar essencial deste projecto era a criação do Homem Novo, assumido como um 
cidadão com uma elevada consciência nacional, empenhado na reconstrução nacional e comprometido com uma Nova Sociedade, sem racismo, tribalismo, regionalismo etc. (FARRÉ, 2014, p. 202; GONÇALVES, 2018, p. 1664; PAREDES, 2014, p.146; SUMICH, 2008). De facto, a criação do Homem Novo era também um projecto assimilacionista em que o português era um elemento importante, tal como ocorrera no período colonial. A única diferença assentava apenas nos objectivos: projecção de um estado-nação unitário, em vez da estruturação de uma sociedade colonial. O português, ao desempenhar o papel de língua veicular, assegurava a união entre os cidadãos moçambicanos, ajudando a imaginar um estadonação com uma ideologia socialista, dentro das fronteiras territoriais. Como explica Fernando Ganhão, primeiro reitor da Universidade Eduardo Mondlane, num discurso em 1979, sobre o papel da língua portuguesa:

Teria sido impensável que em 25 de Junho de 1975, se tivesse escolhido uma das várias línguas moçambicanas para língua nacional, porque as querelas que trazia fariam de certo perigar a existência do nosso estado uno, teriam impossibilitado a unidade que criamos no seio do nosso Partido Frelimo e impedido as vitórias que já alcançámos na edificação das bases materiais e ideológicas para a construção da sociedade socialista. A decisão de se optar pela língua portuguesa, como língua oficial na R.P.M. [República Popular de Moçambique], foi uma decisão política meditada e ponderada visando atingir um objectivo, a preservação da unidade nacional e a integridade do território. A história da apropriação da língua portuguesa, como factor de unidade, nivelador das diferenças, veio desde a criação da Frelimo em 1962. (GANHÃO, 1979, p. 2).

Daí que, para além de língua oficial, o português foi projectado como símbolo de unidade nacional, embora esta situação nunca tenha sido registada na constituição. De facto, a ideia de identidade nacional tem sido associada às línguas autóctones, designadas como línguas nacionais ou línguas moçambicanas. Por exemplo, a constituição de 2004, actualmente em vigor, intitula o Artigo 9 como referente às "línguas nacionais" e nele se afirma que "O Estado valoriza as línguas nacionais como património cultural e educacional e promove o seu desenvolvimento e utilização crescente como línguas veiculares da nossa identidade". O facto é que nenhuma 
língua autóctone se estende por todo o território nacional e o seu uso oficial é esporádico, quase sempre como alternativa à língua portuguesa. Algumas já são usadas como língua de ensino no ensino primário, mas apenas nas classes iniciais, enquanto o aluno vai desenvolvendo o domínio da língua portuguesa. O seu uso é bastante significativo na comunicação intra-étnica, principalmente no seio familiar e nos meios rurais, embora sejam amplamente faladas também nos meios urbanos, contrariamente ao português que quase não é falado nos meios rurais.

A adopção do português como língua oficial e símbolo de unidade nacional promoveu a sua expansão, principalmente porque também se ampliou a rede escolar, onde a língua portuguesa foi durante muito tempo o único meio de instrução, com excepção de alguns casos nas escolas primárias onde se implementa o ensino bilingue. Conforme mostra a tabela 1, o censo de 2007 já dava indicações de que aproximadamente metade da população assumia que sabia falar português (50,3\%), uma tendência que se manteve no último recenseamento geral realizado em 2017 (47,4\%).

Tabela 1 - Percentagem de falantes de português (LP) e de línguas bantu (LB), como Língua Materna (L1) e como Língua-Segunda (L2) em Moçambique

\begin{tabular}{ccccc}
\hline Ano & $\mathbf{L P}=\mathbf{L} 1$ & $\mathbf{L P}=\mathbf{L} 2$ e $\mathbf{L B}=\mathbf{L} 1$ & $\mathbf{L P}=\mathbf{L 1}+\mathbf{L} \mathbf{2}$ & $\mathbf{L B}=\mathbf{L 1}$ e $\mathbf{L P}=\mathbf{0}$ \\
\hline $\mathbf{1 9 8 0}$ & 1,2 & 23,2 & 24,4 & 75,6 \\
$\mathbf{1 9 9 7}$ & 6,0 & 33,0 & 39,0 & 661,0 \\
$\mathbf{2 0 0 7}$ & 10,4 & 39,9 & 50,3 & 49,7 \\
$\mathbf{2 0 1 7}$ & 16,6 & 30,8 & 47,4 & 52,6 \\
\hline
\end{tabular}

Fonte: Elaboração própria, com base em Conselho Coordenador do Recenseamento (1983), Chimbutane (2012), Firmino (2000, 2005) e INE (2019).

Um aspecto crucial na expansão do português em Moçambique terá sido a transformação do seu papel políticosocial através da qual é assumido como língua de unidade no seio do movimento nacionalista, extravasando o seu papel de instrumento de colonização. Passa a ser uma marca simbólica fundamental na imaginação e emergência da nação moçambicana, usada pelos nacionalistas de Moçambique. 
Deste modo, depois da independência, o português não é considerado uma herança incómoda (ROSÁRIO, 1982) e, por isso, é naturalmente usado em todas as funções oficiais, desde os círculos estatais administrativos do Estado até às instituições de ensino. Por outro lado, devido à diversidade etnolinguística do país, e com a mobilidade populacional incrementada pela independência, nas zonas urbanas, principalmente, criouse um ambiente para uma maior interacção entre cidadãos falantes de línguas diferentes, o que os impelia a recorrer ao português, língua que era promovida, conforme anteriormente referido, como símbolo de unidade nacional. Por exemplo, mesmo em ambientes onde se sabia que havia cidadãos que não entendiam português, evitava-se a tradução, como uma forma de induzir as pessoas a usar a língua, ainda que não a dominassem perfeitamente, isto é, tendo em conta o modelo europeu, que era o assumido como português correcto. A preocupação pela correcção era, muitas vezes, minimizada, a favor do uso, desde que a mensagem pudesse ser percebida. Iniciou-se, assim, a aceleração do processo de disseminação da língua, em maior escala relativamente ao que ocorrera no período colonial, quer pela exposição a ambientes onde se usava a língua, nas suas variadas formas de uso, quer, sobretudo, pela aprendizagem no ambiente escolar. Como comentou Mia Couto, ícone da literatura moçambicana:

\footnotetext{
Na realidade, as autoridades moçambicanas não mudaram a sua política linguística e o português permanecia na sua condição de língua oficial e unificadora. Fala-se hoje mais português em Moçambique que se falava na altura da Independência. $\mathrm{O}$ governo moçambicano fez mais pela língua portuguesa que os quinhentos anos de colonização. Mas não o fez por causa de um projecto chamado lusofonia. Nem o fez para demonstrar nada aos outros ou para lançar culpas ao antigo colonizador. Fê-lo pelo seu próprio interesse nacional, pela defesa da coesão interna, pela construção da sua própria interioridade. (COUTO, 2009, p. 192-193).
}

\section{A escola como factor disseminador da língua portuguesa}

As políticas da massificação do ensino tornaram-se o veículo essencial do alargamento da comunidade de falantes de português disseminados por todo o país, apesar das limitações impostas pela rede escolar, que não cobria todo 
o território nacional, concentrando-se nas zonas urbanas, e pela escassez de recursos humanos (professores) e materiais (meios didácticos adequados), o que acabava afectando a aprendizagem e domínio da língua.

Com a independência nacional, houve uma necessidade de se reorganizar o sistema educacional. No âmbito dos novos pressupostos ideológicos que orientavam a política educacional, houve a necessidade de uma reformulação dos programas de ensino de português, de modo a se retirar toda a carga colonial (o que não significou a retirada de aspectos de língua e cultura portuguesa considerados importantes numa formação universal). Por exemplo, a disciplina de português, em todos os níveis, foi talvez a que teve uma maior reformulação dos seus programas, ao mesmo tempo que deixava de dispor, com algumas excepções, de professores qualificados. Sobretudo, um aspecto saliente é que o processo de ensino de português passou a contar com professores que não eram falantes nativos, sem o domínio da norma da variante europeia, tida como padrão no meio escolar. Por outro lado, com a expansão do ensino, passa a haver um número cada vez maior de estudantes que tinham exposição ao português apenas na sala de aula, sendo predominantemente falantes de uma língua bantu, como língua materna, que usavam correntemente no seu dia a dia. Por outras palavras, a maioria dos novos aprendentes do português em Moçambique o fazia (e ainda o faz) sob a interferência de uma língua materna bantu, sem ter grandes possibilidades de acesso a falantes nativos, para efeitos de comparação e eventuais ajustamentos da sua interlíngua (SELINKER, 1972), o que contribuía para a fossilização de uso e formas desviantes.

O ensino e aprendizagem são afectados pelo o facto de se assumir que em Moçambique a norma europeia do português serve como padrão-orientador, sendo a norma que se espera, pelo menos, oficiosamente, que seja dominada pelos moçambicanos e supostamente difundida pelos meios escolares. Com raras excepções, incluindo entre os professores, muitos cidadãos não usam (e dificilmente poderão usar) o português, tal como é padronizado na variante europeia, em função dos contextos sociais em que estão inseridos, que lhes induzem a competências comunicativas diferentes daquelas que são reconhecidas como devidamente válidas no ambiente 
escolar. Muitos alunos, apesar de usarem a língua portuguesa, pelo menos os que já estão no nível superior, recorrem, q uotidianamente, a formas desviantes, a um português diferente do que é sancionado na escola, o que se nota nos diferentes domínios da língua, desde os fonético-fonológicos aos pragmático-discursivos. Citando, Robate (2006):

(...) É assim que na escola moçambicana, as crianças, na sua diversidade linguística - umas falantes de português, ou como língua materna, ou como língua segunda, e outras, fora dessa condição, por conhecerem só uma ou mais línguas nativas, são confrontadas com a língua portuguesa numa única variedade, cuja importância lhe é reconhecida por servir à comunicação nacional e internacional e porque é a que se usa na literatura científica e técnica. Não sendo conhecida pela maioria das crianças, gera-se, desde a primeira etapa de aprendizagem da "nova língua" grande expectativa sobre o "erro": este é simplesmente tomado como sendo "transgressão" à norma padrão que a escola pretende passar para o aluno. E, paradoxalmente, essa transgressão é tomada como motivo do fracasso escolar do aluno, uma vez que traduz falta de aprendizagem. Relativamente à realidade moçambicana, porque a maioria das crianças nem sequer conhece a língua portuguesa, o que se faz, com essa opção, é à partida promover o fracasso de numerosas crianças na escola. (ROBATE, 2006, p. 55-56)

Em função do contexto político-social, económico e linguístico-cultural, aliado aos mecanismos do seu ensino, cimentaram-se formas do português moçambicano que acabam sendo reprimidas nas escolas, apesar de serem correntemente usadas, talvez porque ainda não se fizeram estudos suficientemente adequados para a redefinição da norma em Moçambique, o que, eventualmente, permitiria outras formas de abordagem pedagógica do ensino da língua. Estes estudos poderiam igualmente permitir uma definição adequada da posição da língua portuguesa em Moçambique, para se ultrapassar a assunção de que ela é conhecida da mesma forma por todos os cidadãos em todo o país, principalmente pelas crianças, quando se iniciam na escola.

É verdade que a maioria dos cidadãos em Moçambique não tem o português como língua-materna (L1), mas deve-se reconhecer que esses para quem o português não é a sua L1 apresentam um perfil diferenciado, o que talvez justifique 
procedimentos pedagógicos diferenciados. Para alguns casos, apesar de o português não ser a sua língua materna, as crianças circulam em ambientes onde se expõem ao português, por exemplo, no meio familiar ou através dos meios de comunicação social, como a televisão, de tal sorte que, quando chegam à escola, a língua não é totalmente estranha. Para outros casos, principalmente nos meios rurais recônditos do país, quando as crianças chegam à escola, o português é uma língua totalmente desconhecida, entrando primeiramente em contacto com ela apenas quando começam a frequentar a escola e usando-a (se a usarem) apenas em actividades dentro da sala português). Neste segundo caso, o português é perfeitamente uma língua alóctone, sendo que os alunos são monolíngues numa outra língua, geralmente uma das línguas bantu faladas no país, à data da entrada na escola, ao contrário do caso anterior, em que os alunos são, de certo modo, bilíngues, conhecendo uma língua bantu e, de certo modo, o português, na altura da entrada na escola. Poderá, também, haver casos de crianças monolíngues em português. Trata-se, portanto, de situações diferentes, que, creio, justificariam uma abordagem pedagógica diferenciada. $\mathrm{O}$ ensino de português ressente-se desta situação, na medida em que a maioria dos alunos são apenas tidos como aprendentes de português, como língua-segunda, uma categoria que ofusca factos relevantes no processo de ensino-aprendizagem. Já há melhorias no processo de planificação do ensino, porque já foi introduzido o ensino bilíngue no Programa do Ensino Básico para as crianças que vão à escola sem terem nenhum domínio da língua portuguesa.

Outro aspecto com papel importante na forma como o português é disseminado relaciona-se com o que se ensina e a forma como se ensina. Embora haja melhorias consideráveis à medida que os programas são reformulados, nota-se uma incidência sobre aspectos estruturais em detrimento de outros relacionados com habilidades discursivas, de tal sorte que os alunos até podem ter conhecimentos sobre o funcionamento da língua (isto é, os aspectos gramaticais, a chamada competência linguística), sem, contudo, ganharem as habilidades necessárias para o seu uso em diferentes situações de comunicação, a chamada competência comunicativa (DE BONA; MACHADO, 2012, p. 42-46; HYMES, 1972, p. 281-282). Ou seja, os alunos não são preparados para se comunicarem adequadamente 
num contexto moçambicano. Como afirma Robate (2006), que estudou o currículo de formação de professores primários na disciplina de Língua Portuguesa em Moçambique:

\begin{abstract}
O que aqui se pode dizer, por inferência, e sem exagero, porque baseado na experiência como formador, é que as regras da gramática que se ensinam, não só nos CFPPs (e nas escolas), mas também nas instituições superiores de formação de professores, não implicam o uso, o "como moçambicanamente se diz"; é uma gramática de nomenclaturas e classificações (a ciência linguística), e em relação a essa metalinguagem o formando deve demonstrar ter domínio, para fins da retórica académica, preocupada apenas com mecanismos internos da linguagem padronizada, como se ela existisse independentemente, sem influências externas. A questão da variação da língua não passa de um mero conhecimento teórico que o formando adquire para completar a lista teórica de substantivos, pronomes, adjectivos, preposições, advérbios, conjunções, interjeições... Entendida como conjunto de regras, a gramática que vai às nossas escolas, onde as crianças usam uma variante da língua portuguesa cada vez mais enriquecida, é uma gramática que, procurando ensinar "regras que devem ser seguidas", ao invés das "regras que são seguidas" pelos falantes moçambicanos (dirigentes, professores universitários e do ensino secundário e primário, órgãos de comunicação social, e funcionários dos diversos ramos da actividade social), acaba transtornando as crianças, os jovens e adultos que frequentam a escola. (ROBATE, 2006, p. 93-94).
\end{abstract}

\title{
Nativização da língua portuguesa em Moçambique
}

A expansão da língua portuguesa conduz não só ao aumento dos seus falantes como também a diversificação dos seus usos, ao mesmo tempo em que é socialmente apropriada, principalmente nos centros urbanos, como se pode notar no surgimento de um segmento populacional que a usa como principal meio de comunicação em todas as suas interacções, incluindo no meio caseiro ou familiar. Nalguns casos, a língua portuguesa chega a ser a língua materna $(10,4 \%$ no censo de 2007 e 16,6\% no censo de 2017), entre falantes que já não dominam as línguas autóctones.

A apropriação social da língua portuguesa conduz a sua nativização, quer por simbolicamente passar a ser uma nova entidade quer pela incorporação de novos traços linguísticos, que a vão peculiarizando. A nativização simbólica ocorre 
quando transcende a condição de língua colonial passando a ser reconhecida como parte intrínseca do processo de edificação de um estado-nação em Moçambique. Simultaneamente, ganha novas características estruturais, principalmente na oralidade, no nível da pronúncia e inovação lexical, embora ocorram também mudanças gramaticais. Esses novos traços linguísticos emergem em função do contexto sociolinguístico em que a língua é usada, tendo em conta a região, etnicidade, estatuto social ou a L1 dos falantes, o que significa que há muita variação nas formas de português que vai emergindo. Não há estudos amplos, que abranjam todo o país, para se obter uma visão ampla e sistematizada da emergência da nativização estrutural da língua portuguesa em Moçambique, embora haja alguns indícios obtidos principalmente tendo em conta o caso da região de Maputo, que podem servir de exemplos. Segue-se a exemplificação de alguns casos, que serão considerados tendo em conta a pronúncia, léxico e aspectos morfossintácticos.

\section{Pronúncia}

Interferência fonólogica

Um aspecto que distingue o português falado em Moçambique resulta da influência do sistema fonológico das línguas autóctones, todas elas do grupo bantu, que constituem a L1 da maioria dos cidadãos. Por exemplo, os falantes como L1 de Emakhuwa (P23, na classificação de Guthrie das línguas bantu) tendem a ensurdecer as consoantes oclusivas, uma vez que na sua língua materna, contrariamente ao português, não ocorre uma oposição fonológica entre as consoantes oclusivas surdas e sonoras. Exemplos:

- Debate [tepati] vs. [Português europeu: dəbati]

- Dedo [tetu] vs. [Português europeu: dedu]

- Barato [paratu] vs. [Português europeu: baratu]

Similarmente, um traço amplamente conhecido relacionase com falantes de Gitonga (S62, segundo a classificação de Guthrie) como LI, que estão familiarizados com um sistema fonológico com uma consoante fricativa velar [y], que não faz parte do sistema fonológico do português, onde o fonema mais 
próximo é uma consoante velar sonora [g]. Consequentemente, os falantes de Gitonga como L1, no seu uso de português, tendem a "fricatizar" a consoante oclusiva velar, como nos seguintes exemplos:

- Apagar [apayar] vs. [Português europeu: apagar]

- Agora [ayora] vs. [Português europeu: agora]

- Gato [yatu] vs. [Português europeu: gatu]

Este tipo de interferência é muito comum e pode ser detectado com falantes das várias línguas. Há indícios de que mesmo os que não são propriamente falantes de uma língua bantu como L1 podem sofrer a mesma influência, desde que estejam numa região onde uma determinada interferência é dominante.

\section{Reestruturação silábica}

No português europeu, as sílabas podem ser CV, CVC ou CCV, como em " jogo ", que é uma palavra com a estrutura silábica CV-CV, ou "fritar", que é CCV-CVC. Por seu turno, as línguas bantu, permitem sílabas do tipo $(\mathrm{C}) \mathrm{V}$ e, consequentemente, falantes nativos de línguas bantu não estão familiarizados com sílabas que contenham grupos consonânticos ou terminem com uma consoante. Esta situação conduz a que muitos falantes de português tendam a reestruturar as sílabas que não se conformem com a estrutura CV. Assim, muitos falantes de português em Moçambique tendem a inserir vogais epentéticas para quebrar grupos consonânticos ou para fechar as sílabas, de modo a que todas elas sejam do tipo CV. Exemplos:

- Bruto [burutu] vs. [Português europeu: brutu]

- FRELIMO [fєrelimu] vs. [Português europeu: frelimu]

- Acreditar [akeriditari] vs. [Português europeu: akreditar] 


\section{Léxico/Vocabulário}

\section{Empréstimos}

Uma das características principais que distingue o português usado em Moçambique é a incorporação de elementos lexicais oriundos das línguas locais. Alguns são usados amplamente em todo o país, outros são comuns apenas em algumas regiões. São usados, primariamente, para fazer referência a aspectos endógenos da realidade local, que não têm expressão no modelo europeu da língua portuguesa, porque desconhecidos no contexto europeu. Noutros casos, o uso deste tipo de palavras expressa mútua solidariedade entre os interlocutores e é uma forma de asserção de uma identidade local. Alguns exemplos são:

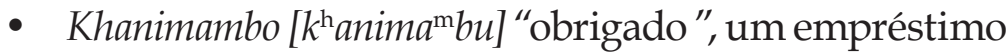
de Xironga/Xichangana, duas línguas bantu faladas no sul de Moçambique, amplamente usado no país;

- Massala [masala], fruto local de uma árvore cientificamente conhecida por Strychnos spinosa;

- Lifete [lifete], doce que é um composto de amendoim torrado, pilado misturado com grãos de mandioca seca (tapioca);

- Chiguinha/Xiginya [Jigina], um cozinhado que é uma mistura de mandioca, amendoim e vegetais, normalmente cacana (planta conhecida cientificamente por Momordica balsamina, parecida com a que dá o fruto popularmente conhecido no Brasil por melãode-são-caetano, melão amargo, fruto de cobra ou melãozinho).

Há também o caso de empréstimos morfologicamente adaptados, que se referem a prácticas relacionadas com a vivência política, económica, social e cultural do país na actualidade. Estes empréstimos, normalmente oriundos das línguas bantu, comportam-se morfologicamente como uma palavra da língua portuguesa, mas têm a particularidade de apresentarem um significado que resulta de redefinição do sentido original do seu étimo para poder exprimir realidades locais. É o caso de: 
- pandar "desenrascar, inventar algo para ganhar a vida" (de kupanda, em Xironga/Xichangana, uma das línguas locais);

- marandzas ("namorada interesseira"), de kurandza, ("gostar, amar", em Xichangana);

- dumba-nengue ("mercado informal"), que literalmente significa " confia na tua perna", já que o vendedor tem de fugir constantemente da polícia, é um composto formado a partir de duas palavras em Xichangana, kudumba ("confiar") and nenge ("perna");

- tchunga-moyo ("mercado informal"), que literalmente significa "coração corajoso", composto formado a partir de duas palavras em Cindawu, kutchinga (ter coragem) e moyo ("coração").

Alguns empréstimos que se tornam comuns no português falado em Moçambique podem ter outras origens para além das línguas bantu. Várias palavras são incorporadas no português em Moçambique, na sequência dos contactos com os países fronteiriços, principalmente a África do Sul, influência das telenovelas brasileiras, intercâmbios artísticos, por exemplo, com músicos angolanos, etc. Em muitos destes casos, os efeitos são efémeros, embora haja palavras deste tipo com um impacto mais duradoiro. Exemplos:

- Txilar ("festejar, celebrar"), importado do português de Angola;

- Rochar ("ter insucesso na carreira musical, ter um lançamento musical que é um fracasso no mercado"), importado do português de Angola;

- Jurado ("membro de um júri"), em vez de "júri", tal como é comum no modelo inspirado no português europeu, importado do português de Brasil;

- Car wash ("lugar onde se faz a lavagem de viaturas"), importado do Inglês da África do Sul;

- Bottle store ("local de venda de bebidas alcoólicas"), importado do Inglês da África do Sul. 


\section{Mudança semântica}

O português em Moçambique está em transformação igualmente porque as palavras existentes no banco lexical da língua adquirem novos significados e usos. Por exemplo, ocorrem casos de transferência semântica, como com a palavra "cabrito", uma palavra portuguesa que pode ser usada metaforicamente para fazer referência a um corrupto. Dentro deste sentido, surge também o verbo cabritar, formado segundo processos morfológicos regulares no sistema gramatical da língua portuguesa, para significar "extorquir dinheiro, corromper, pedir propina (como se diz no Brasil)". No português falado em Moçambique faz sentido uma frase como "Este polícia é um cabrito e está a cabritar", com o significado de que o polícia é um corrupto e está extorquindo dinheiro. É um uso da palavra "cabrito" que deriva do dito popular "o cabrito come onde está amarrado", que implicita que qualquer um deve tirar vantagens do seu posto de trabalho.

Há também casos de expansão de significado, como com a palavra "dormir" que no português-padrão europeu só se refere a entidades animadas. No português falado em Moçambique pode-se referir também a entidades inanimadas, como na frase, "o carro dormiu lá fora durante a noite", com o sentido de que "o carro permaneceu lá fora durante a noite". Nas línguas bantu, o verbo correspondente refere-se a entidades animadas e inanimadas. Daí a interferência.

\section{Morfossintaxe}

Sobregeneralização do género masculino e seu uso por defeito

Muitos falantes de português em Moçambique obliteram a distinção entre os géneros masculino e feminino, que percorre a organização morfossintáctica das frases. Tal é comum nas frases longas, havendo tendência de usar o masculino. Exemplos:

- Frelimo não está parado vs. [português europeu: Frelimo não está parada]. 
Alteração de padrões gramaticais relacionados com formas de tratamento

A variante europeia da língua portuguesa faz uma distinção entre as formas "Tu" e "Você" (ou "o senhor" e ainda "vós", mas já pouco usado), a que se associam marcas morfossintácticas correspondentes para cada situação. Contudo, alguns falantes de português em Moçambique não seguem estes padrões morfossintácticos, havendo indicações da anulação desta forma de sinalização da distinção pragmática, como na frase "A morte só nos tirou a tua voz (...). Tenha paz", que no português europeu oferece a possibilidade de ser ou $A$ morte só nos tirou a tua voz (...). Tem paz (indicando proximidade, intimidade ou informalidade) ou A morte só nos tirou a sua voz (...). Tenha paz (indicando formalidade, reverência ou respeito). Na primeira parte da frase usa-se a forma "tu", que deveria denotar intimidade, proximidade, informalidade e na segunda a forma você, que indica formalidade, reverência e respeito. De facto, o que é mais comum é o uso recorrente da forma $t u$, sem que necessariamente indique intimidade, proximidade, informalidade. O conhecimento introspectivo do autor permite assumir que os efeitos pragmáticos que se pretenda evocar são expressos por meios paralinguísticos, como entoação, postura cinética ou proxémica, etc. Contudo, trata-se de um campo que ainda não foi devidamente explorado para se ter uma posição mais substanciada.

\section{Construções passivas dativas}

No português europeu as passivas dativas são agramaticais, contrariamente às línguas bantu, em que o sujeito de uma oração passiva pode desempenhar o papel temático de benefactivo, manifestando, portanto, o caso dativo. Alguns falantes de português sofrem a interferência das línguas locais e produzem frases na passiva em que o sujeito é um beneficiário, e não um paciente, como em "eu fui dado um rebuçado com a mãe". Repare-se o uso da preposição "com", no lugar de "por", fenómeno que também é comum. A saliência do dativo entre alguns falantes moçambicanos de português também é notória na preferência pelos pronomes dativos, em detrimento dos acusativos, como nas seguintes frases: 
- Atacaram-lhe e levaram o carro vs. [português europeu: atacaram-no e levaram o carro];

- Levou-lhe para o hospital vs. [português europeu: levou-o para o hospital].

Recentemente, ouviu-se um entrevistado num programa noticioso de uma estação "televisiva" local afirmando que " os jogadores devem serem investidos desde a sua formação"(Jornal da noite da STV, 23 de Setembro de 2020), querendo dizer que se deve investir nos jogadores desde a sua formação. $\mathrm{O}$ verbo "investir" não é transitivo e, portanto, não exige um paciente como objecto. Consequentemente, a frase não pode ter os jogadores como sujeito, pois na frase activa corresponderia a um beneficiário, com funções de um objecto indirecto.

\section{Transitivização de verbos}

Alguns verbos ergativos e inacusativos, como nascer são usados por alguns falantes moçambicanos de português como verbos transitivos, como em "ela nasceu dois filhos na África do Sul", que é uma frase agramatical no português europeu. $\mathrm{O}$ sentido que se quer transmitir nesta frase é de que ela teve dois filhos na África do Sul, ou seja, o verbo passa a ter o significado de "dar a luz, parir" É mais um caso de interferência, já que verbos semanticamente aproximados nas línguas bantu, como kupswala ("dar a luz, parir", em Xironga), guvelega ("dar a luz, parir", em Gitonga) são transitivos e, portanto, permitem objectos directos.

\section{Padronização da língua portuguesa em Moçambique: desafios e perspectivas}

O português em Moçambique não é uma entidade homogénea, pois, como qualquer outra língua, inclui variações. De facto, considerando que a nativização das línguas de origem europeia é similar a crioulização (MUFWENE, 1994, p. 21-31; SCHNEIDER, 2003, p. 257; 2007, p. 61), o português de Moçambique pode ser considerado como um continuum de variedades, que incluem, num extremo, formas basilectais, mais afastadas do português europeu e no outro, as formas acrolectais, muito próximas do português europeu. Entre os 
dois extremos, há muita variação e todas as formas linguísticas que compõem esta variação são distintamente moçambicanas.

As formas acroletais ainda são reconhecidas como o português perfeito e constituem o modelo promovido e ensinado no meio escolar. Também são usadas na administração pública, vida política, meios de comunicação, etc. Contudo, não é rigorosamente o português de Portugal que se pretende que se fale em Moçambique, como também não são as formas linguísticas que subvertem totalmente a norma europeia. Por isso que, apesar de o padrão europeu ser considerado oficialmente pelas autoridades e elites sociais como a forma correcta de português e ser promovido nas escolas, há também manifestações de rejeição social do sotaque branco, localmente designado também por afinar, "um tipo de pronúncia afectada, entendida como semelhante à do " Português português » ou à do "Português dos moçambicanos brancos " (FIRMINO 2005, p. 115). Portanto, a nativização não implica simplesmente a rejeição per se do padrão europeu, mas a sua reavaliação em função de normas locais de uso adequado da língua.

O desafio que se impõe é o estabelecimento e reconhecimento amplo de uma norma-padrão para a língua portuguesa, tendo em conta a sua situação em Moçambique, principalmente os fenómenos relacionados com a sua nativização. Para o efeito, será necessário acelerar o trabalho de descrição linguística e consequente elaboração de materiais de referência, nomeadamente, dicionários, gramáticas, prontuários, etc.

A localização da norma-padrão permitiria uma melhor orientação dos processos didáctico-pedagógicos, evitando-se o desfasamento entre o que se pretende que os alunos saibam e o que o ambiente social permite aprender e assimilar com facilidade. Assim, esta endonormativização acabaria tendo consequências nas estratégias de ensino e na produção de materiais de ensino. Por outro lado, o reconhecimento na escola de aspectos que reflectem a moçambicanização da língua, acabaria acelerando a sua disseminação. A disseminação implica apropriação e esta não pode ocorrer sem uma estabilidade endonormativa. Dando-se, através do ensino, legitimidade aos usos locais da língua, alguns desviantes em relação à norma implicitamente seguida, seria uma forma de 
se reforçar a relação do cidadão com a língua, minimizando-se a percepção de exogenia que ainda perdura sobre ela, porque se iria desfazer a discrepância entre "regras que devem ser seguidas", (do modelo europeu), e as 'regras que são seguidas', (do modelo moçambicano), pelos falantes moçambicanos (dirigentes, professores universitários e do ensino secundário e primário, órgãos de comunicação social, e funcionários dos diversos ramos da actividade social) (ROBATE, 2006, p. 94).

A legitimação da nativização do português através de modelo endonormativo seria também um reconhecimento do carácter multilíngue e da sociedade moçambicana, uma vez que ela reflecte a convivência e complementaridade entre as diversas línguas que constituem o repertório linguístico do cidadão moçambicano. $\mathrm{O}$ português em Moçambique não existe fora desta complementaridade com as línguas bantu, da mesma forma que estas também são afectadas pela sua convivência com o português.

\section{Notas finais}

A nativização da língua portuguesa é, de facto, um processo da reconstrução linguística, que promove a sua integração na sociedade moçambicana. Com esta constatação pode ser problemático associar estas línguas com o elitismo (MYERS-SCOTTON, 1993) e com a alienação das massas do desenvolvimento nacional (DJITÉ, 2008). Afinal, de que línguas se está a falar? Em muitos países africanos, como mostra o processo de nativização, as línguas de origem europeia sofreram uma transformação, muitas vezes, em interacção com as línguas locais, adquirindo funções, usos e traços estruturais que as tornam potencialmente úteis para reforçar a integração nacional e promover a participação das massas. É necessário apenas que se reconheçam as formas nativizadas através, inter alia, de políticas linguísticas que promovam a estabilidade endonormativa. Portanto, não é o português em si que promove ou não a participação alargada da sociedade, mas a aceitação ou rejeição de certas formas de português ou não para o exercício de cidadania. 


\section{REFERÊNCIAS}

ALEXANDRE, Valentim. Ideologia, economia e política: a questão colonial na implantação do Estado Novo. Análise Social, Lisboa, v. 28, n. 123-124, p. 1117-1136, 1993.

ASHCROFT, Bill. On post-colonial futures: Transformations of a colonial culture. London: Continuum, 2001.

. Caliban's voice: The transformation of English in postcolonial literatures. London \& New York: Routledge, 2009.

BOKAMBA, Eyamba. The Africanization of English. In: KACHRU, Braj. (org.). The other tongue: English across cultures. Urbana, IL: University of Illinois Press, 1982, p. 77-98

DE BONA, Camila; MACHADO, Sheila. Competência linguística e comunicativa: um paralelo entre duas abordagens lingüísticas no contexto de ensino de Língua Inglesa. BELT - Brazilian English Language Teaching Journal, Porto alegre, v. 3, n. 1, p. 40-52, jan/jun 2012. Disponível em: https:// revistaseletronicas.pucrs.br/ojs/index.php/belt/article/ view/10325. Acesso em: 25 set. 2020.

BOURHIS, Richards. Language policies and language attitudes: Le monde de la Francophonie. In: RYAN, E. \& GILES, H. (org.). Attitudes toward language Variation. London: Edward Arnold, 1982, p. 34-62.

CHIMBUTANE, Feliciano. Panorama linguístico de MoçambiqueAnálise dos dados do III recenseamento geral da população e habitação de 2007. Maputo: INE, 2012.

CONSELHO COORDENADOR DO RECENSEAMENTO. Recenseamento geral da população: Informação Pública. Maputo: INE, 1983.

COUTO, Mia. E se Obama fosse africano? e outras interinvenções. Lisboa: Editorial Caminho, 2009.

CRAVEN, Matthew. Between law and history: The Berlin Conference of 1884-1885 and the logic of free trade. London Review of International Law, v. 3, n. 1, 2015, p. 31-59, 2015. 
Disponível em: https://doi.org/10.1093/lril/1rv002. Acesso em: 12 abr. 2019.

DJITÉ, Paulin G. The Sociolinguistics of Development in Africa. Clevendon: Multilingual Matters, 2008

ESCOLASUPERIOR COLONIAL. Decreto n. 16.199: regulamento do trabalho indígena. Legislação Ultramarina (Diplomas Fundamentais). Lisboa: Escola Superior Colonial,1954. p. 57-169.

FARRÉ, Albert. Assimilados, régulos, Homens Novos, moçambicanos genuínos: a persistência da exclusão em Moçambique. Anuário Antropológico, Brasília, UnB, v. 40, n. 2, p. 199-229, 2014. Disponível em: http://journals.openedition. org/aa/1443. Acesso em: 24 set 2020.

FÉRAL, Carole de. Les «variétés» du français en Afrique. Stigmatisations, dénominations, réification: à qui la faute? Cahiers de sociolinguistique, CAIRN, n. 15, p. 41-53, 2010-1. Disponível em: https://doi.org/10.3917/csl.1001.0041. Acesso em: 21 set. 2020

FERREIRA, Manuel. Que futuro para a lingua portuguesa em África? Linda-A-Velha: ALAC/Edições A Preto e Branco, 1988.

FIRMINO, Gregório. A Situação Linguística de Moçambique: Dados do II Recenseamento Geral da População e Habitação de 1997. Maputo: INE, 2000.

A "questão linguística" na África pós-colonial: o caso do Português e das línguas autóctones em Moçambique. Maputo: Texto Editores, 2005.

Nation-statehood and linguistic diversity in the postcolony: The case of Portuguese and indigenous languages in Mozambique. In: ANCHIMBE, Eric A.; MFORTEH, Stephen A. (org.). Postcolonial Linguistic Voices: Identity choices and representations, Berlin/Boston: Walter de Gruyter, 2011, p. 99-117.

GANHÃO, Fernando. O papel da língua portuguesa em Moçambique. In: I SEMINÁRIO NACIONAL SOBRE O ENSINO DA LÍNGUA Portuguesa. Maputo: Mozambique, 1979. 
GONÇALVES, António Cipriano Parafino. Modernidades Moçambicanas e Educação: da crise de referências ao vazio de sentido. Educação \& Realidade, Porto Alegre, v. 43, n. 4, p. 1653-1676, out/dez. 2018. Disponível em: https://doi. org/10.1590/2175-623676545. Acesso em: 21 set 2020.

GONÇALVES, Perpétua. Génese do Português de Moçambique. Lisboa: Imprensa Nacional-Casa da Moeda, 2010.

O português em África. In: RAPOSO, Eduardo Buzaglo Paiva; NASCIMENTO, Maria Fernanda Bacelar do; MOTA, Maria Antónia Coelho da; SEGURA, Luísa; MENDES, Amália (org.). Gramática do Português. Lisboa: Fundação Calouste Gulbenkian, 2013, p. 157-178.

HYMES, Dell. On communicative competence. In: PRIDE, J. B.; HOLMES, Janet. (org.). Sociolinguistics: Selected Readings. Harmondsworth, England: Penguin books, 1972, p. 269-293

INE-INSTITUTO NACIONAL DE ESTATÍSTICA. IV recenseamento geral da população e habitação 2017- Resultados definitivos. Maputo: Instituto Nacional de Estatística, 2019.

INVERNO, Liliana. A transição de Angola para o português vernáculo: estudo morfossintáctico do sintagma nominal. In: CARVALHO, (org.). Português em contacto. Madrid, Frankfurt: Iberoamericana/Editorial Vervuert, 2009, p. 87-106.

KACHRU, Braj B. The Pragmatics of Non-Native Varieties of English. In: SMITH, Larry E. (org.) English for Cross-Cultural Communication. London: Palgrave Macmillan, 1981, p. 15-39. Disponível em: https://doi.org/10.1007/978-1-349-16572-8_2. Acesso em: 25 set. 2020.

Models for non-native englishes. In: KACHRU, Braj B. (org.). The other tongue: English across cultures. Urbana, IL: University of Illinois Press, 1982, p.31-57.

LIPSKI, John M. The Spanish of Equatorial Guinea. The dialect of Malabo and its implications for Spanish dialectology. Series: Beihefte zur Zeitschrift für romanische Philologie, 209. Mouton: De Gruyter, 1985. 
The Spanish language of Equatorial Guinea. Arizona Journal of Hispanic Cultural Studies, v. 8, n. 1, p. 115-130, jan. 2004. Disponível em: http://www.jstor.org/stable/20641705. Acesso em: 20 set. 2020.8, n.1, p. 115-130.

LOWENBERG, Peter H. Non-Native Varieties of English: Nativization, Norms, and Implications. Studies in Second Language Acquisition, Cambridge, vol. 8, n. 1, p. 1-18, February 1986. Disponível em: https://doi.org/10.1017/S0272263100005805. Acesso em: 20 Set 2020.

MARTINEZ, Esmeralda Simões. O trabalho forçado na legislação colonial portuguesa - o caso de Moçambique (1899-1926). Dissertação de mestrado, Universidade de Lisboa, 2008, 331p.

MAKONI, Sinfree; MAKONI, Busi; ABDELHAY, Ashraf; MASHIRI, Pedzisai. Colonial and post-colonial language policies in Africa: Historical and emerging landscapes. In: SPOLSKY, Bernard (org.). The Cambridge handbook of language policy. Cambridge: Cambridge University Press, 2012, p. 523-543. Disponível em: https://doi.org/10.1017/CBO9780511979026.032. Acesso em: 21 set 2020.

MANNESSY, Gabriel. De la subversion des langues importées: Le Français en Afrique Noire. In: CHAUDENSON, Robert; ROBILLARD, Didier. (org.). Langues, Économie et Développement, Institut d'Études Créoles et Francophones, Université de Provence, Diffusion: Didier Érudition, 1989, v.1, p. 133-145

MATEUS, Maria Helena Mira. Mudança da língua no tempo e no espaço. In: A língua portuguesa em mudança. Lisboa: Caminho, 2005, p. 23-30.

MELO, Vanessa de Pacheco. Urbanismo português na cidade de Maputo: passado, presente e futuro. Urbe - Revista Brasileira de Gestão Urbana, v. 5, n. 1, p. 71-88, 2013. Disponível em: https:// doi.org/10.7213/urbe.7786. Acesso em: 19 set 2020

MACAGNO, Lorenzo. A Invenção do Assimilado - Paradoxos do Colonialismo em Moçambique. Lisboa: Colibri, 2020. 
MINDOSO, Andre Victorino. Os assimilados de Moçambique: da situação colonial à experiência socialista. 2017. 254f . Tese (Programa de Pós-Graduação em Sociologia), Setor de Ciências Humanas, Universidade Federal do Paraná, Curitiba, 2017

MOAG, Rodney. Life Cycle of Non-Native Englishes. In: Kachru, B. (org.). The Other Tongue: English Across Cultures. Urbana-Champaign: University of Illinois Press, 1982, p. 270288.

MOAG, Rodney; MOAG, Louisa B. English in Fiji: Some Perspective and the need for language planning. Fiji English Teacher's Journal, n. 13, p. 2-26, 1977.

MUFWENE, Salikoko. New Englishes and criteria for naming them. World Englishes, vol. 13, n. 1, p. 21-31, [S.1.], 1994.

MYERS-SCOTTON, Carol. Elite closure as a powerful language strategy: the African case. International Journal of the Sociology of Language, n. 103, p. 149-163, 1993. Disponível em: https://doi. org/10.1515/ijsl.1993.103.149. Acesso em: 24 set. 2020.

NEWITT, Malyn. A history of Mozambique. Bloomington, Indianapolis: Indiana University Press, 1995.

NEWITT, Malyn. A history of Portuguese overseas expansion, 1400-1668. London \& New York: Routledge, 2005.

A short history of Mozambique. Johannesburg/Cape Town: Jonathan Ball Publishers, 2018.

PAREDES, Marçal de Menezes. A construção da identidade nacional moçambicana no pós-independência: sua complexidade e alguns problemas de pesquisa. Anos 90, Porto Alegre, v. 21, n. 40, p. 131-161, dez. 2014.

ROBATE, Simão Artur. Curriculo de Formação de Professores Primários na Disciplina de Lingua Portuguesa em Moçambique: Um Repensar de Seus Fundamentos Teóricos. Piracicaba, São Paulo: 2006. 
ROSÁRIO, Lourenço. Língua portuguesa e cultura moçambicana: De instrumento de consciência e unidade nacional a veículo e expressão de identidade cultural. Cadernos de Literatura, Coimbra, n. 2, p. 117-134, 1982.

SCHNEIDER, Edgar W. The dynamics of New Englishes: From identity construction to dialect birth. Language, v. 79, n. 2, p. 232-281, 2003.

Postcolonial English: Varieties around the world. Cambridge: Cambridge University Press, 2007.

SELINKER, Larry . Interlanguage. International Review of Applied Linguistics in Language Teaching, v. 10, n. 3, p. 209-230, 1972. Disponível em: https://doi.org/10.1515/iral.1972.10.1-4.209. Acesso em: 22 set. 2020.

SHAKESPEARE, William. A tempestade. Tradução de Rafael Raffaelli. Florianópolis: Ed. da UFSC, 2014.

SUMICH, Jason. Construir uma nação: ideologias de modernidade da elite moçambicana. Análise Social, v. 42, p. 319-345, 2008.

TUNDE-AWE, Bola Margaret. Nativization of English language in a multilingual setting: The example of Nigeri. Academic Journal of Interdisciplinary Studies, v. 3, n. 6, p. 485-492, 2014. Disponível em: https://doi.org/10.5901/ajis.2014.v3n6p485. Acesso em: 28 maio 2019. 


\section{ABSTRACT}

The Rise of an Endogenous Norm of Portuguese in Mozambique: Challenges and Perspectives

The article overviews the situation of the Portuguese language in Mozambique, showing aspects related to its implantation in the country, since the colonial period to the present moment. After showing some historical evidence, it points out that the Portuguese language is undergoing a process of symbolic and structural nativization, by which peculiar ways of its use are emerging. The article finalizes by discussing challenges and perspectives posed by nativization, given that recognition of an endogenous standard is in need.

Keywords: Mozambique;

portuguese; nativization; norm;

standardization.

Gregório Domingos Firmino é Doutor em Antropologia Linguística pela Universidade da Califórnia em Berkeley. Estados Unidos. Tem leccionado disciplinas que tratam de aspectos relacionados com a intersecção língua, cultura e sociedade, como os casos de Sociolinguística e Antropologia Linguística. Interessa-se por questões relacionadas com o multilinguismo em Moçambique, principalmente os fenômenos decorrentes da adopção e uso de português e da sua coexistência com as línguas autóctones e outras. É professor da Faculdade de Letras e Ciências Sociais, da Universidade Eduardo Mondlane, Maputo, Moçambique 